\title{
TRANSITANDO: ALGUNAS HERRAMIENTAS PARA EL DOCENTE SOBRE EDUCACIÓN VIAL
}

Silvia Luz de Luca

Docente escuela primaria rural n.ำ 342 (EGB), Allen, Río Negro, Argentina.

\begin{abstract}
Agradecimientos:
A las organizaciones Luchemos por la vida y Seguridad vial, por brindarse a la comunidad y permitirme utilizar la información publicada en sus sitios; a mis amigas docentes, por ayudarme con bibliografía y alentarme en el proyecto.
\end{abstract}

\section{PRESENTACIÓN}

Cada mañana, cuando me dirijo a la escuela con mis compañeras, apretaditas pero confortablemente sentadas en un auto, veo pasar a mis ex alumnos en bicicleta rumbo a la escuela secundaria, sin luces, sin ropa adecuada, con algún hermano o compañero sentado en el caño, haciendo zig-zag $o$ en doble fila, esquivando autos en la ruta. $Y$ me pregunto: ¿No les enseñamos las normas de circulación? ¿No los prevenimos de los posibles accidentes? ¿Qué hicimos como docentes, o qué no hicimos?

Una rápida encuesta entre docentes de mi ciudad, me confirmó lo que pensaba: no se enseña Educación Vial. Salvo los colores del semáforo en los primeros grados y alguna que otra señal, que se dan más porque aparecen en los textos asociados a otros conocimientos, no se considera un tema prioritario, no se evalúa, ni figura específicamente entre las expectativas de logros.

Este trabajo tiene que ver con eso, buscar las mejores maneras de iniciar a nuestros niños en Educación Vial, tanto de escuelas rurales como la mía, como de escuelas urbanas o suburbanas, de grandes o de pequeñas poblaciones.

"La ruta es el lugar donde la vida es menos valorada" (Sauvy). La defensa de la vida del ser humano debe replantearse como el máximo y supremo valor, no únicamente desde un enfoque individual sino dirigido hacia la especie toda. El derecho a la vida comprende el derecho a la salud física, mental y social. El Pacto de San José de Costa Rica expresa en su artículo 5o: " toda persona tiene derecho a que se respete su integridad física, moral y psicológica".

Todo lo que se avanza en tecnología y modernización del parque automotor, debería ir acompañado por programas de adecuación de las rutas, señalizaciones, sanciones, etc., pero si los usuarios no respetan las normas, no sirve de mucho.

Lo que se necesita es modificar la mentalidad del usuario de la vía pública e intensificar la capacitación de éste, es decir, se necesita que el hombre se socialice en la vía pública y para ello el único arma efectiva es la educación en la escuela, debemos formar conciencias. Si bien, muchas instituciones están trabajando en esto con campañas de toda índole, es en la escuela donde deben recibir la educación 
necesaria para ser peatones, pasajeros o conductores responsables. De esto tienen conciencia los países más desarrollados, como lo demuestran sus programas educativos en todos los niveles.

Con esta investigación y recopilación de datos y actividades, deseo brindar a los docentes la mayor información posible que pueda serles útil para apropiarse y transmitir los conocimientos necesarios, acercarles modelos que se realizan en nuestro país y en otros, ayudarlos a imaginar y poner en práctica nuevas ideas, teniendo en cuenta:

- El niño peatón

- El niño ciclista

- $\quad$ El niño pasajero

\section{LOS NIÑOS EN LA CALLE}

Algunas consideraciones acerca del comportamiento de los niños en la calle, extraído y traducido del artículo "Bambini per strada". (1)

Satisfacción de necesidades: un niño busca principalmente la satisfacción de sus propias necesidades. Para él jugar, moverse, ser puntual para ir a la casa o a la escuela, alcanzar a sus padres del otro lado de la calle o buscar la pelota son cosas más importantes que tener en cuenta la circulación; por continuar aquello que ha iniciado, un niño es capaz de tirarse contra un vehículo, que él ha visto, pero que obstaculiza su objetivo.

La muerte: un niño no teme a la muerte.

Para él la muerte es un juego, a menudo juega a hacerse el muerto y después levantarse y revivir. Un niño no tiene miedo de morir pero tiene miedo de ser regañado por un adulto que se vea obligado a frenar.

El ambiente seguro: un niño tiene a menudo la impresión de estar seguro, por ejemplo piensa que nada le puede ocurrir si sus padres o unos adultos están cerca de él, si se encuentra dentro de su casa o de su escuela.

Las falsas imágenes del niño: los objetos no tienen pera él el mismo significado que para los adultos.

La calle: para él es un lugar de juego sin el control de los padres.

Los automóviles: confía en ellos, les parecen humanos (faros = ojos, etc.)

Los pasos peatonales: en su mente son lugares donde nada de malo le puede ocurrir.

El instinto de imitación: un niño imita siempre al adulto. Si alguien cruza la calle, él también cruza, sin darse cuenta de que en pocos segundos la situación cambia; si está de la mano de un adulto se conforta con la idea de la ausencia de peligro.

Antes de los 10 ó 12 años, un niño tiene muchas dificultades en la circulación porque, 


\section{UN NIÑO NO ES UN ADULTO EN MINIATURA}

En la Unión Europea, el aumento generalizado de los peligros y del tránsito, han impulsado a los padres a reducir la libertad de movimientos de sus hijos, con importantes consecuencias para su salud y este dato ha modificado la vida en esas ciudades.

Los padres que han decidido proteger a sus hijos sacándolo de los peligros del tránsito, han comprendido aquello que la psicóloga sueca Stina Sandels resumió en esta frase:

\section{El niño no puede adaptarse al tránsito.}

Algunos de los resultados de su grupo de trabajo son fundamentales para comprender los problemas de fondo del comportamiento de los niños en la calle:

\section{La impulsividad}

Los niños se dejan guiar por sus impulsos de diferente modo que los adultos, si ven algo excitante del otro lado de la calle, se olvidan cada cosa que sabes del tránsito y se dirigen en pos de su objetivo con total desatención.

\section{La necesidad de moverse}

Los niños tienen una innata necesidad de correr, de saltar, de trepar. Para un niño caminar con calma y tranquilidad es tan extraño como para un adulto correr. Este dato aumenta en modo automático el riesgo de incidentes en medio del tráfico en el cual es descontado que cada peatón se mueva con habilidad.

\section{Miedo y pánico}

Aunque lo niños pongan atención al tráfico, a menudo no se comportan correctamente, porque el tráfico es tan complicado que se asustan y en ellos se produce una sensación de pánico. Un niño noruego de la escuela primaria describe la situación de esta manera: "Muchas veces me asusto de los camiones porque van tan fuerte que cualquier día pueden subirse a la acera, entonces me escapo a la calle, pero allá hay autos también".

Otro niño dice: "Algunas veces sobre la senda peatonal ellos casi me saltan encima. Ellos van encima de los niños. Lo he visto en el diario!"

\section{La visión}

El campo visual de un niño es reducido respecto del de un adulto, no tienen la misma capacidad para adaptarse a las condiciones del tráfico. No concentran la atención en más de un objeto a la vez y no pueden pasar de ver un objeto cerca de otro lejos con la misma facilidad de un adulto. El niño mira primero un objeto, luego otro, después un tercero, pero al contrario de los adultos, ellos no pueden percibir rápido los tres juntos. La habilidad de dar una inmediata interpretación a todo lo que sus ojos ven depende de la madurez de una persona, y a tal madurez se llega alrededor de los 16 años, de acuerdo a lo que afirma Piaget.

\section{La altura}

También la altura crea dificultades cuando se debe hacer frente al tráfico. Los ojos de un niño de siete años se encuentran a una altura de alrededor de $100-125 \mathrm{~cm}$, mientras que los de un adulto están 50 $\mathrm{cm}$ más arriba generalmente. En la práctica, para el niño es imposible ver sobre el techo de los autos 
estacionados y a menudo no ven ni siquiera sobre el capó o el baúl. Un vehículo que aparece de improviso es inmediatamente visto por un adulto, pero puede no ser visto por un niño, y a su vez el niño puede no ser visto por el automovilista.

\section{La audición}

Entre el $3 \%$ y el $30 \%$ de los niños de seis años no identifican correctamente de donde proviene un sonido. También un adulto algunas veces se equivoca, pero compensa mejor el error. Para un niño un error puede traer consecuencias peligrosas: un error puede empujarlo fácilmente a correr en dirección a un auto que llega de un lado inesperado.

\section{Comprensión de las palabras o de los consejos de la educación vial}

A los 7 años el niño comprende cerca de la mitad de las palabras que son usadas normalmente para la educación vial de niños de 5 años. En consecuencia se debe poner atención a las palabras que se usan cuando se enseña el comportamiento del tráfico, a veces se debe enseñar cosas muy complicadas con palabras tan simples que las reglas del tráfico no son comprendidas. Por eso se debe recordar que la tarea de la educación vial es dar información en un modo tal que pueda ayudar a los niños a hacer frente al tráfico adecuadamente.

\section{Comprensión del significado de importantes señales viales.}

Como con las palabras, en lo que respecta a las señales viales, los niños encuentran difícil de entender el significado, los símbolos a menudo no son comprendidos. La mitad de los niños de seis años comprende 3 carteles entre los 11 importantes para su seguridad; cerca del $50 \%$ de los niños de 8 años entiende 7 carteles de los 11 y el 50\% de los de 10 años comprende 10. Según afirma Piaget, los niños desarrollan el pensamiento abstracto cuando entran en la adolescencia, por esto el resultado descrito no debería sorprendernos.

\section{Capacidad de distinguir la derecha de la izquierda}

La capacidad de pensar en términos abstractos es necesaria para distinguir entre derecha e izquierda. Los niños pequeños permanecen a menudo confusos por el hecho de que un lado de la calle a veces es "la derecha" y el otro"la izquierda" y viceversa. Una encuesta ha demostrado que sólo el $58 \%$ de los niños de seis años distinguen entre derecha e izquierda, a los siete años la percepción sube al 72\%, a los nueve años al $92 \%$.

\section{Capacidad de abstracción y análisis}

El adulto puede escuchar, ver, atravesar la calle y al mismo tiempo elaborar toda la información útil, mirar y adaptar el comportamiento respecto a lo observado. El niño puede hacer una sola cosa a la vez: por ejemplo mira o escucha o decide atravesar la calle. Esto significa que puede absorber solo una parte del flujo de información que se origina de los automóviles en veloz movimiento de direcciones opuestas, los variados sonidos emitidos, las varias señalizaciones. No es sorprendente que una niña despierta, que ha seguido cursos de educación vial, hija de padres inteligentes, diga como hace para atravesar la calle de esta manera: "Primero miro a la derecha, después a la izquierda y después de nuevo a la derecha, después estoy ahí parada temblando y después corro". 
La información presentada puede ser resumida en la siguiente afirmación: Los niños no son bastante maduros para hacer frente al tránsito moderno, y la educación o la enseñanza no pueden cambiar este dato. Un niño un día se comporta como un perfecto peatón, pero puede ser totalmente incapaz al día siguiente.

Nadie espera que un bebé de seis meses camine; nosotros sabemos que su sistema nervioso, la musculatura y el esqueleto no son suficientemente maduros para hacerlo, pero parece que esperamos que un niño de 7 años sea capaz de atravesar una calle de mucho tránsito sin compañía.

Veinte años después de las conclusiones de Stina Sandels, el tráfico es aún más complejo; los niños tienen entonces menos experiencia del ambiente vial, haciéndose adolescentes conquistan una relativa independencia y se vuelven la categoría más riesgosa del tránsito.

Si queremos disminuir el riego para los estudiantes, nosotros debemos tomar medidas a favor de la seguridad no sólo delante de la escuela, sino también adoptar medidas de moderación del tráfico en el área, porque los incidentes con estudiantes no suceden sólo frente a la escuela y, por otra parte, informar a los conductores de estas características de los niños.

(1) www.xoomer.vi rgilio.it/ffrera

\section{LAS BICICLETAS}

En Argentina, la mayoría de los ciclistas circulan sin respetar las normas básicas del tránsito, tanto en lo relativo a la circulación (sentido del tránsito, respeto al semáforo, etc), como en cuanto a las disposiciones sobre el vehículo para poder circular (luces, reflectantes).

La población de ciclistas, al igual que el resto de la población, no ha recibido educación vial de ninguna clase, tampoco para conducir bicicletas. No comprenden que , en tanto circulan por la calzada con un vehículo deben, como conductores, conocer y respetar las reglas del tránsito.

Si el tránsito en general se encuentra descuidado por parte de las autoridades de aplicación de la ley, lo que puede apreciarse con solo circular un rato por cualquier calle, los ciclistas parecen invisibles para ella. Las bicicletas no existen para los agentes de tránsito. Esta indiferencia refuerza en los ciclistas la creencia de que las normas de tránsito no son para ellos.

Luchemos por la Vida, ha elaborado un "Plan de educación vial para ciclistas" , el cual fue presentado a las autoridades municipales de la ciudad de Buenos Aires en 1997. El mismo consta de un programa teórico-práctico, para capacitación de conductores seguros de bicicletas, desde 12 años en adelante.

Este programa se sumaría a las campañas de concientización masiva para ciclistas que la Asociación viene desarrollando desde 1992 en radio y televisión y al programa "ESCUELAS POR LA VIDA" de educación vial para escuelas de EGB y polimodal que, desde 1994, en su modalidad de cuatro visitas incluye el módulo "Conducir seguro en bicicleta" en los talleres para alumnos del tercer ciclo. Pero estas campañas no abarcan todo el país, desgraciadamente.

Algunas Instituciones han publicado en diversos medios las reglamentaciones y recomendaciones para los usuarios de bicicletas, es el caso de ACU. (Asociación de Ciclistas urbanos) 
Sitio Web: www.geocities.com/acubicicleta

\section{ACTIVIDADES (EN DISTINTOS PAÍSES )}

Hace unos años, el Consejo Provincial de Educación de Río Negro, elaboró una secuencia de entrenamiento para las distintas edades, muy interesante sobre todo para los docentes, pero no se pone en práctica.

En la ciudad de Buenos Aires se creó una Escuela de Educación vial, pero actualmente está cerrada. Era una ciudad en miniatura. En poco más de tres años, 94.000 alumnos primarios y secundarios porteños recorrieron sus 880 metros de asfalto en kartings y bicicletas o como peatones. El objetivo es que aprendieran a ser automovilistas responsables y peatones prudentes. Se inauguró en agosto de 2000, pero su historia ya tiene final. La primera escuela de educación vial de la ciudad, y la segunda en importancia en América latina, cerró sus puertas.

En Italia, se crearon numerosos proyectos de Educación vial en todos los niveles educativos. Muy conocido es el proyecto de la ciudad de Fano:

Francesco Tonucci, en su libro "La ciudad de los niños. Un modo nuevo de pensar la ciudad", cuenta la experiencia iniciada en 1991 por la Municipalidad de Fano, Italia, y que hoy encuentra el interés y la adhesión de muchas ciudades italianas y extranjeras, propiciada por UNICEF y la Facultad Latinoamericana de Ciencias Sociales (FLACSO). Si bien en este caso se trató de cambiar la ciudad para beneficio de los niños, estos recibieron una intensa preparación en educación vial.

Otras ciudades como Brescia, Torino, Roma o Bergamo, también presentaron proyectos interesantes, algunos de los cuales se describen a continuación a modo de ejemplo.

Percorso didattico di educazione stradale (Recorrido didáctico de educación vial (año 1996/97)) (2)

Finalidad: Promover en los alumnos el respeto consciente de las normas de circulación, a través del conocimiento y el comportamiento.

CLASE $1^{\underline{a}}$

1) Adquirir algunos conocimientos inherentes a la educación vial:

a) percibir formas y colores,

b) identificar los conceptos espaciales como vertical, horizontal, largo, ancho, etc.

c) Interiorizar los conceptos topológicos (dentro, fuera, derecha, izquierda, cerca, lejos, arriba, abajo, etc)

2) Conocer el ambiente de la calle, con observaciones guiadas, en recorridos habituales, adquiriendo el vocabulario específico (acera, senda peatonal, etc.)

3) Reflexionar sobre algunas normas de comportamiento a tener en cuenta sobre la acera.

\section{CLASE $2^{\mathrm{a}}$}

1) En un recorrido habitual (escuela-casa...) saber leer las "señas" (sendas peatonales, semáforos, ...) y comprender las indicaciones. 
2) Durante un recorrido habitual, reconocer los carteles de las calles y su significado

3) Conocer las normas que regulan el comportamiento de los peatones sobre la acera, identificando también los incorrectos.

4) Saberse orientar en su propio ambiente y saber representar y contar recorridos simples.

\section{CLASE $3^{a}$}

1) Adquirir la nomenclatura técnica respectiva : carretera, ciclovía, etc.

2) Saber leer mapas simples referidos a su propio territorio, individualizando las vías de comunicación.

3) Internalizar las normas que debe respetar el peatón:

a) Sobre la calle con acera

b) Sobre la calle sin acera

c) sobre los cruces peatonales

d) en los cruces sin senda peatonal

e) el cruce después de descender de un vehículo.

\section{CLASE $4^{\mathrm{a}}$}

1) Saber clasificar los vehículos y conocer algunas normas relativas al equipamiento de las bicicletas.

2) Leer en el propio contexto ambiental la señalación vertical: señales de peligro, de restricción e indicación.

3) Individualizar las normas de comportamiento de los ciclistas.

4) Conocer las principales vías de comunicación de su propio ambiente, haciendo uso también de mapas del territorio provincial y regional.

\section{CLASE $5^{\mathrm{a}}$}

1) reconocer las señales viales.

2) identificar las normas de circulación de los ciclistas

3) clasificar las vías de comunicación en el propio contexto.

4) leer mapas carreteros, reconociendo la simbología usada.

5) conocer algunos elementos de seguridad relativos a la circulación.

(2) www.members.it.tripod.de/stradamica

\section{Percorsi sicuri (Recorridos seguros) (3)}

En el primer ciclo, los niños tienen un limitado conocimiento de las calles de su barrio o ciudad. Por eso se los llevó a recorrer la zona más conocida por todos (el perímetros de la escuela, la iglesia, la rotonda, los negocios, etc). 
Cada grupo tenía un rol preciso:

-escuchar los sonidos y ruidos, elegirlos, clasificarlos.

-identificar olores, perfumes y clasificarlos

-identificar las zonas seguras para el peatón y aquellas peligrosas.

La salida estuvo documentada con fotografías y filmaciones breves.

Con variaciones de actividades, el proyecto abarca cuatro clases.

Todos los datos, observaciones y propuestas se discutieron a nivel colectivo, se seleccionaron y organizaron para producir textos escritos para compartir con otros alumnos.

Las múltiples fases del trabajo fueron documentadas de diferentes formas: textos, tablas, mapas, fotos... Se organizó luego un cuadernillo que fue entregado a la Comuna local y una encuesta para conocer el medio de transporte que usan los niños de otras escuelas habitualmente para desplazarse a los diferentes lugares.

(3)//space.tin.it/scuola/ffrera

La Administración Provincial de Pesaro e Urbino, ha creado un Laboratorio de Educación vial que se propone desarrollar acciones educativas y formativas, así como respetar el artículo 230 del C.d.S (código vial) que asigna a la escuela la obligación de desarrollar programas inherentes a tal disciplina. Se considera particularmente urgente desarrollar tales actividades a las escuelas próximas a calles con mucho tránsito .

La Universidad de Brescia, patrocinada por la Comisión Europea ha elaborado guías y convenios para desarrollar programas de este tipo, así como manuales editados por grupos suizo-italianos.

Numerosos sitios de internet ofrecen a los niños de todas las edades juegos, textos, acertijos y muchas experiencias para poder transferirlas al aula

La Policía de tránsito de Bergamo, junto a la Comuna, realizó un proyecto para el 2004, puntualizando los contenidos específicos para cada ciclo de la escuela, aportando material de multimedia en forma gratuita.

Estos proyectos, que se llevaron a cabo con éxito en algunas ciudades italianas, pueden servir de ejemplo para elaborar otros proyectos, salvando las diferencias de lugar o las características de cada zona. Hay innumerables experiencias relatadas en la web, pero en general no varían mucho de las citadas.

Experiencia de intervención socio-comunitaria en Colmenar Viejo. Madrid.

Se realiza desde hace 7 años y ha sido desarrollada desde un modelo interdisciplinar que combina la actuación de recursos personales del municipio en el diseño y desarrollo del programa, y en el que participa toda la comunidad Educativa del sector en su aplicación.

La secuencia de implantación del programa se ha efectuado en cinco fases:

1) Evaluación Inicial

2) Sesiones teóricas 
3) Sesiones prácticas (circuito de tráfico)

4) Evaluación final

5) Evaluación del programa.

\section{Guía de Educación Vial de España}

La finalidad de esta guía es satisfacer la demanda por parte de un amplio sector docente de una publicación que pudiera ser utilizada indistintamente para ampliar o insistir en ciertos aspectos relacionados con la seguridad vial de sus alumnos, o como ejemplo práctico para llevar a cabo la secuenciación de objetivos y contenidos en el Proyecto Educativo de Centro y en el Proyecto Curricular, y que también sugiriese posibles líneas de trabajo para la elaboración de las Programaciones de Aula.

La obra se estructura en dos apartados en los que se tratan los siguientes temas:

- En el primero, después de analizar los antecedentes, concepto y justificación de la Educación Vial, se exponen cómo han sido integrados sus objetivos y contenidos en las áreas que componen el currículo de la Educación Primaria. Posteriormente y tras analizar los comportamientos viales y el desarrollo evolutivo de los alumnos/as de esta etapa educativa, se determinan las orientaciones didácticas y metodológicas, los criterios relacionados con el desarrollo del Proyecto Educativo de Centro y del Proyecto Curricular, y la secuenciación por ciclos de objetivos, contenidos y criterios de evaluación.

- En el segundo, se presentan tres unidades didácticas en las que se adapta la anterior secuenciación a los tres ciclos de etapa y a las características propias de determinados centros. Sugiriéndose diversas actividades que pueden ser de utilidad a los docentes en sus programaciones. Tras el desarrollo de cada unidad didáctica se ofertan editadas en formato A4, para ser fotocopiadas y aplicadas directamente en el aula, las correspondientes ejemplificaciones en las que se concretan algunos de los objetivos, contenidos y actividades expuestas en la programación general presentada anteriormente.

Posibilidades Didácticas

- Ampliar o insistir en ciertos aspectos relacionados con la seguridad vial de los alumnos. - Ejemplo práctico para llevar a cabo la secuenciación de objetivos y contenidos en el Proyecto Educativo de Centro y en el Proyecto Curricular, y, que también, sugiriese posibles líneas de trabajo para la elaboración de las Programaciones de Aula.

En este proyecto han participado el Ministerio de Educación y Ciencia, a través del Centro Nacional de Información y Comunicación Educativa (CNICE) - antes Programa de Nuevas Tecnologías de la Información y Comunicación (PNTIC)-. Además del Ministerio del Interior y la Dirección General de Tráfico (DGT).

El docente puede solicitar de forma gratuita, previa solicitud, la edición en el Centro Nacional de Información y Comunicación Educativa (CNICE).

En Francia, el Ministère de L'ÉDUCATION NATIONALE DE LA RECHERCHE ET DE LA TECHNOLOGIE, DIRECTION DE L'ENSEIGNEMENT SCOLAIRE, ha realizado una campaña que abarca los tres ciclos de la escuela primaria, llamado "La sécurité routière à l'école primaire", donde se tiene en 
cuenta todos las regiones, departamentos y comunas, como así también todos los organismos que directa o indirectamente tienen que ver con el tránsito (Asociaciones de transportes, Centros de información y prevención, Organismos profesionales, Escuelas, Policía, Gendarmería, Servicios de equipamiento, Ministerios de defensa, Interior, Educación, Economía, Deportes, etc.)

Publicaron una revista detallando el proyecto, sus actores, objetivos, actividades, sugerencias y experiencias de clases.

En ese país hasta un niño de 6 años sabe que no puede cruzar la calle si no es por la senda peatonal. Este proyecto es un ejemplo digno de imitar.

Los expertos reunidos en el III Congreso Internacional sobre Políticas Europeas de Tránsito, celebrado los primeros días de noviembre de este año en Barcelona, han concluido que el objetivo primordial es conseguir una movilidad responsable que garantice un espacio público seguro y educar permanentemente a los ciudadanos en seguridad vial.

\section{METODOLOGÍAS}

La idea es introducir la Educación vial como una materia específica, pero también como un contenido transversal, es así como se puede trabajarlo en Lengua, Ciencias Sociales o Naturales, Matemática, Tecnología, Educación Física o Plástica (ver apartado Actividades). En este último caso, se corre el riesgo de no sistematizarlo y por lo tanto no evaluarlo, por lo que pierde jerarquía.

Si se toma como un eje integrador e institucional, desde todos estos ángulos se pueden realizar actividades que refuercen y concienticen a los alumnos.

El Docente tiene varios desafíos. Por un lado capacitarse en una "nueva" materia de la que debe aprender sus contenidos, pero aún hay otro factor preponderante: concientizarse a si mismo, significando ello la internalización de los efectos que pueden lograrse si se da la justa valoración a esta peculiar enseñanza.

Transmitir parte de sí, es tarea cotidiana de un docente, y cuando sus enseñanzas obtienen o generan resultados a la vista logran proyectar en los niños una mayor motivación.

"Resulta común ver en la vía pública a padres (algunos docentes) que transportan a sus hijos adoptando actitudes conductivas contradictorias con la propia relación de compromiso afectivo y familiar que obviamente se presume existe. Así, y a modo de ejemplo, podemos citar, el desarrollo a altas velocidades, la falta de colocación del correaje de seguridad, la transportación en asientos delanteros de menores donde la ley fija edades determinadas, ubicados sobre las "faldas", etc. Agregamos a ello, que también los exponen a las eventualidades de arriesgadas maniobras, operaciones de ascenso y descenso, posibles choques, o bruscas frenadas, y en contraposición con esa actitud, esas mismas personas demuestran, por lo general, un excesivo celo en otras situaciones cotidianas de la vida real, previniendo posibles golpes o caídas de sus hijos, cuidándolos y previniendo o defendiendo de cualquier peligro o ataque que se presente contra ellos.

De lo que se trata en Educación Vial es de que los niños no lleguen a ser "esos adultos" y que mientras sean niños sepan como "defenderse" de las malsanas conductas viales de sus propios progenitores y el medio que los rodea, sin perjuicio de que una correcta Educación Vial debe incorporar a los padres en esos compromiso, mas allá de que muchas experiencias en tal sentido hayan sido sencillamente un fracaso. Algunas experiencias han demostrado que las personas de mayor condición social con acceso al confort y una vida digna en términos económicos, es la que ha "fallado" a la hora de integrarse a un taller de Educación Vial. Por el contrario, aquellas personas de humilde condición y con limitaciones económicas han respondido en mayor y mejor medida en tal sentido. Al parecer estos grupos de la escala social se encontrarían mas "maleables" en su proceso de socialización. “ 
Parte del artículo especialmente escrito para la Revista Vía $\mathrm{n}^{*} 5$ de Inforvial. FUNDAMENTOS PARA LA ELABORACIÓN DE UN PROGRAMA DE EDUCACIÓN VIAL DESTINADO A DOCENTES, PROFESORES E INSTRUCTORES VIALES por Daniel Zuccarelli

Por todo esto es que insisto en que debemos "concientizarnos" nosotros mismos, conocer y poner de manifiesto con el ejemplo, nuestra propia Educación Vial. Es imposible educar niños diciendo "haz lo que yo digo pero no lo que yo hago".

La Educación Vial ha de tener elementos complementarios o accesorios como soporte, así, la eficacia de la labor docente puede ser reforzada, desde el punto de vista de campañas, mediante una labor cotidiana a través de publicaciones, manuales de instrucciones, boletines, informaciones y otros medios similares que pueden reforzarse mediante la participación de entidades de apoyo, clubes de servicio, fabricantes y aseguradores de la zona, así como también revistas de automovilismo y medios de comunicación social. El docente buscará la participación de la policía local, Municipalidad, grupos de teatro, y comunidad en general, para complementar su propuesta.

Las estrategias a utilizar serán lo más variadas posibles: el juego y su valor formativo, la expresión corporal y su espacio parcial-total-social, la educación musical y la preparación de canciones con contenidos de Educación Vial, el cuento y su metodología formativa, la expresión plástica y su metodología de trabajo en las áreas de acceso a la Educación Vial, y valerse de medios como videos, películas, revistas, diarios, etc.

Es importante tener en cuenta:

- Desarrollo de un proyecto integrado interdisciplinario.

- $\quad$ Análisis de videos de Educación Vial.

- Cálculos de distancia-diferencias de velocidades.

- Análisis de accidentes de tránsito.

- Trabajos de producción.

Priorizar siempre aquellas actividades lúdicas que fomentan la interacción, la participación y la reflexión en grupo. Reconocer las vivencias cotidianas de los niños y niñas, revalorizar las actitudes relacionadas a la Educación vial. Basándose en las ideas y experiencias previas confrontar situacionesproblemas con posibles soluciones o analizar actitudes correctas o incorrectas.

\footnotetext{
"Utilizar un enfoque pedagógico "constructivista", para el logro de nuevos conocimientos significativos, es decir, conocimientos comprensivos, no-memorísticos, que permanezcan en el tiempo y les sean de utilidad para el logro de soluciones a problemas teóricos o prácticos de su vida. Para que estos aprendizajes se concreten, desarrollar actividades participativas, en la modalidad de talleres, donde el educando es el verdadero protagonista de la acción, procurando estimular su capacidad reflexiva y de observación para la resolución de situaciones problemáticas, partiendo de su nivel madurativo y de la realidad en la que vive y que le es significativa, para ampliar sus horizontes y brindarle posibilidades para su vida comunitaria.", Lic. María Cristina Isoba
}

La propuesta es enfocar la enseñanza de la educación vial desde la perspectiva de la concepción del tránsito como un sistema que hacemos entre todos. Ya no se trata solamente del niño que va a su escuela, se trata del niño que va a transitar, a interactuar con los demás en un espacio compartido y que les pertenece a todos; para lograr su propósito debe tener siempre en cuenta a los demás. 
El enfoque participativo y social del tránsito, moviliza la reflexión y el sentido auto-crítico, $Y$ en los niños mayores y adolescentes, estimula la espontánea crítica al sistema y la búsqueda de soluciones.

Un objetivo principal de la educación vial debe ser motivar, en los educandos, la conciencia de ser una parte activa y responsable del sistema del tránsito, posibilitándoles, a través del proceso de enseñanzaaprendizaje:

- conocer y comprender la características del mismo y las reglas que lo ordenan.

- comprender los riesgos del sistema (posibilidades de accidentes) y la forma de evitarlos,

- para desarrollar, como participantes del tránsito, actitudes, conductas, y hábitos seguros, responsables y solidarios para el cuidado y respeto de la propia vida y la de los demás, en el espacio compartido de la vía pública,

- contribuyendo a que cada uno de ellos llegue a ser agente de cambios positivos en su comunidad.

\section{PROPUESTAS}

1. Desde la Matemática podemos contribuir a la Educación Vial, utilizando la construcción de polígonos inscriptos en la circunferencia para construir las señales.

Se puede calcular perímetros, longitud de la circunferencia, superficie, cálculos con los ángulos, trabajar fracciones, simetría, etc.

2. Desde la Educación física también hay numerosas actividades que se pueden realizar, desde construir recorridos simulando rutas, con obstáculos y señales para carreras, transitando a pie, en triciclo (los más pequeños), o en bicicletas, respetando las señales, sancionando a los que no las cumplen, hasta imitar las señas de los agentes de policía de tránsito.

El sitio efdeportes.com propone un Proyecto de educación vial a través del área de Educación Física, sumamente interesante vinculados con la bicicleta, sin olvidar las obligaciones de peatón. Proponen conocer en profundidad su mecánica, su física, sus posibilidades; una instancia en el Centro de Educación Ambiental y presentar una Revista que culmine el trabajo educativo desarrollado. Todo esto adecuado a los distintos niveles.

3. También desde la Lengua, aprovechando un texto informativo, analizar y comparar situaciones, opinar, juzgar, ponerse en el lugar de...etc.

Preparar alumnos como comunicadores sociales. La idea es generar espacios en los medios de comunicación gráficos, radiales y televisivos, con un alto protagonismo de los niños. Elaborar microprogramas, secciones, artículos, avisos publicitarios o historietas. Este modelo de actividades requiere la capacitación previa de los alumnos por parte de especialistas en los medios de comunicación implicados.

4. Competencias intercomunitarias de educación vial. Aquí movilizamos a los diferentes actores de las instituciones escolares en competencias locales. Pueden ser concursos de preguntas y respuestas, pruebas de tránsito o consignas de trabajo comunitario.

Directivos, docentes, alumnos y padres pueden asumir roles diferentes en las competencias, según las distintas consignas. Por ejemplo: listar todos los vehículos mal estacionados entre determinadas calles 
desde las 10 hasta las 13 del sábado. O bien, registrar y describir las situaciones de peligro ocasionadas por ciclistas alrededor de la plaza principal en determinado día y hora. Es bueno contar con la adhesión de los medios locales para la difusión de la competencia.

Sugerencias pedagógicas

- Profundizar acerca de los roles que desempeña el hombre en la vía pública, utilizando técnicas de dinámica grupal para diferenciarlos (debate, "roles playing", sociodrama. Etc.)

- Una pequeña obra de teatro o de títeres es un recurso excelente para que los chicos vivencien estas temáticas. Guiarlos para que la escriban y luego la representen. Es una buena oportunidad para construir el retablo de títeres.

- Planificar una actividad, netamente investigativa, referida a los requisitos que deben reunir los conductores para lograr su habilitación como tales, hacer que los alumnos concurran a la Municipalidad y averigüen sobre los mismos (el procedimiento administrativo, los tiempos de duración de los trámites, los exámenes necesarios, etc.) y luego, que redacten un informe al respecto. Igual propuesta de investigación, para los temas referidos a los conductores y a los servidores de la vía pública.

- El diario es una fuente permanente de recursos informativos y formativos en esta temática, por lo que le sugerimos su utilización sistemática, advirtiéndole acerca de la fuerza dramática que lamentablemente puede tener la realidad.

En el sitio www.educ.ar se ofrece un proyecto integrado con Matemática y Lengua para trabajar con imágenes en computadora, es una buena opción para las escuelas que cuentan con ese medio.

Con esta serie de propuestas, propias y ajenas, creo abarcar un amplio panorama de actividades para distintos niveles educativos. El desafío es tratar de ponerlas en práctica.

Debemos tomar en consideración la cantidad de accidentes que se registran a diario por la falta de educación vial de nuestra población. Es la escuela la encargada de crear conciencia en este sentido, de manera que cada docente tiene la obligación moral de trabajar estos contenidos, ya que los niños y jóvenes deben actuar como agentes multiplicadores.

Cada docente debe prepararse en la temática integral de la seguridad y la educación vial porque de esta manera ofrece la mejor herramienta para afrontar situaciones adversas o difíciles de comprender sin los conocimientos necesarios y específicos.

\section{BIBLIOGRAFÍA}

APARICI Roberto, GaRCía MATILLA Agustín. "Lectura de imágenes". Ediciones de la Torre, Madrid, 1986.

RAYNA Silvie, coordinadora de "La educación preescolar" AZ-editora. Buenos Aires, 1999.

“Los niños y el Tránsito", publicación del Consejo Provincial de Educación de Río Negro. 1999

Revista "Novedades Educativas" № 126, Ediciones Novedades Educativas. Buenos Aires, 2001.

Revista "Zona educativa" № 24, Ministerio de Cultura y Educación de la Nación. Junio 1998.

www.arrakis.es 
www.comune.fe.it/cittabambina

www.copetel.com.ar/webs/transito

www.dgt.es/1999eduvial

www.ecos.edu.ar/ecos/transito

www.educ.ar

www.educnet.education.fr/securite

www.escolares.com.ar/cont enidoscurriculares

www.geocities.com/acubicicleta

www.geocities.com/Athens/8940/

www.lagirandola.it

www.luchemos.org.ar

www.nonsoloscuola.org.it

www.members.it.tripod.de/stradamica/

www.pnp.gob.pe/revistaelectronica

www.pntic.mec.es

www.race.es/educación-vialhtm/

www.scuole.provincia.ps.it

www.seguridad-vial.org.ar

//space.tin.it/scuola/ffrera

www.unasca.it/aut_scuola/EducazioneStradale.html

www.vigileamico.it

//xoomer.Virgilio.it/ffrera

www.xtec.es/recursos/clic/cat/act/soci 


\title{
Contactar
}

Revista lberoamericana de Educación

\author{
Principal OEI
}

